\title{
Practising medicine in the global village: use of guidelines and virtual networks
}

\section{Patricia F. Walker MD DTM\&H}

See related guidelines by Pottie and colleagues on page E824 and at www.cmaj.ca/lookup/doi/10.1503/cmaj.090313.

$\mathrm{T}$ he Clinical Preventive Care Recommendations for Newly Arriving Immigrants and Refugees to Canada are launched with this issue. ${ }^{1}$ Immigrant-specific, evidence-based clinical guidelines have been lacking in the medical literature, and these guidelines are an important addition to the world literature on migration medicine. Developed using a rigorous 14-step process for review of the evidence and involvement of relevant experts and stakeholders, these are the first comprehensive published guidelines on preventive care tailored specifically to immigrants and refugees.

In 2010, the number of international migrants is estimated to reach 214 million. ${ }^{2}$ Time taken to circumnavigate the globe since 1850 has decreased from over 365 days to 1-2 days, whereas world population has increased from less than one billion to over six billion. ${ }^{3}$ The United States is expected to be the largest recipient of international migrants in 2010 (42.8 million), followed by the Russian Federation (12.3 million), Germany (10.8 million), Saudi Arabia (7.3 million) and Canada (7.2 million). ${ }^{2}$ However, patient care for international migrants and medical education for clinicians who care for them have not kept pace with world population growth and mobility, resulting in inequities in care and patient outcomes for globally mobile populations.

Refugees and immigrants come from locations throughout the world and thus have widely disparate health concerns and socioeconomic status. Because they migrate most often from underdeveloped countries, they also have much in common. These include more infectious diseases, fewer chronic health concerns initially, language, cultural and structural barriers to care, and all too often, health care providers and health delivery systems less than adequately prepared to care for globally mobile populations. ${ }^{46}$

Health care providers in the 21st century can no longer conceptualize "diseases over there" or "diseases seen here." Each patient needs to be asked two fundamental questions: "Who are you?," thereby assessing genetics, and socioeconomic and cultural issues, and "Where are you from or where have you travelled?," thereby assessing risk of disease prevalence in countries of origin (and of first asylum for refugees and immigrants).

The development of immigrant health guidelines should be based on country or region of origin and data on incidence of

\section{Key points}

- Immigrant-specific, evidence-based clinical guidelines have been lacking, and the Clinical Preventive Care Recommendations for Newly Arriving Immigrants and Refugees to Canada are an important addition to the world literature on migration medicine.

- New technologies, including real-time feedback loops, exist and should be used to improve care for migrants.

- In the future, unmet chronic health and preventive care needs may dwarf the burden of infectious diseases found in migrants; providers and health care delivery systems should work together to reduce health disparities for globally mobile populations.

disease, as well as on specific patient-centred issues including genetic predisposition, such as prevalence of G6PD deficiency, sickle cell trait and other inherited genetic disorders. The Clinical Preventive Care Recommendations for Newly Arriving Immigrants and Refugees to Canada cover wideranging topics, from infectious disease screening (hepatitis B, HIV and tuberculosis) to noncommunicable chronic diseases, mental illness, anemia, oral and visual health, and women's health, including contraception, pregnancy and cervical cancer screening. With evidence-based literature reviews and a Delphi consensus process, recommendations for screening, quality of evidence and clinical considerations are all carefully outlined. The development process included involvement of immigrant groups and relevant experts in specific diseases and immigrant and refugee health. The result is a rigorous, evidence-based set of recommendations for screening globally mobile populations that is applicable to migrants from underdeveloped countries worldwide. The US Centers for Disease Control and Prevention has also recently developed recommendations for screening new refugees on arrival, which are based on a rigorous review process (www.cdc.gov /immigrantrefugeehealth/guidelines/refugee-guidelines.html).

Guidelines that are not geared for immigrants and refugees

Patricia F. Walker is Medical Director, HealthPartners Center for International Health, and Associate Professor, Division of Infectious Disease and International Health, Department of Internal Medicine, University of Minnesota, St. Paul, USA

\section{CMAJ 2011. DOI:10.1503/cmaj.100625}

All editorial matter in CMAJ represents the opinions of the authors and not necessarily those of the Canadian Medical Association. 
may be inadequate to deal with the decline in health status that may occur after arrival in a developed country. Many refugees and immigrants are "healthy migrants," arriving with better health parameters to their new home than natives. That advantage is rapidly lost, and the answer to my favourite question for long-term migrants, "How much did you weigh when you came to the US?" may be a clue to increased risk for diabetes, coronary artery disease, stroke and hypertension. More recent arrivals may also come with significant unmet chronic health needs. ${ }^{7}$ Inequities in preventive health care are particularly challenging. ${ }^{8}$ Early, culturally competent interventions that focus on immigrant lifestyle strengths are needed; we have much to learn from migrants about healthy eating and exercise habits.

\section{Virtual networks}

New technologies exist that should be used to improve care for refugees and immigrants. Refugee camp disease outbreaks and surveys of disease prevalence in refugee camp settings should be used to guide real-time recommendations for empiric treatment both internationally and in resettlement countries. In some US states, electronic disease notification systems provide real-time data to practitioners seeing newly arriving refugees. Similar systems should be expanded and connected both nationally and internationally.

To reduce health disparities for migrants in their country of origin or first asylum, closed feedback loops should be developed - with data from new arrival screenings in Canada, the US and elsewhere being transmitted back to refugee camps and countries of origin - to inform health care in underdeveloped countries, thereby reducing health disparities. In general, less information on health is available for nonrefugee migrants, which may contribute to their health disparities.

In clinic, I have recently seen refugees from Bhutan with profound vitamin $B_{12}$ deficiency. Upon enquiring among the network of refugee health providers in the US, I found that this issue was well known to a health provider in Utah who had noted both a very high prevalence of vitamin $B_{12}$ deficiency as well as strongyloidiasis in Bhutanese refugees (Paul Swoboda, Salt Lake Family Health Center, Utah: personal communication, 2010). At a large immigrant health clinic in the US, refugees from widely varying countries of origin were found to have a substantially greater prevalence of vitamin D deficiency (88\%) than that found in the US National Health and Nutrition Examination Survey (NHANES) (77\%), with more than double the amount of severe deficiency (at $14 \%$ compared with $6 \%$ in the NHANES ${ }^{9}$ ) (Ann Campagna, Ann Settgast, HealthPartners Center for International Health, St. Paul, Minn.: personal communication, 2010). The challenge lies in disseminating such data internationally in real time to providers caring for globally mobile populations. A virtual immigrant health provider consortium may provide a partial solution.

The Clinical Preventive Care Recommendations for Newly Arriving Immigrants and Refugees to Canada are relevant to all providers as we practise patient-centred care in the global village. The long-term goal of guidelines is to reduce health disparities, and the new Canadian guidelines should be rigorously implemented to help achieve this goal.

Competing interests: None declared.

\section{REFERENCES}

1. Pottie K, Tugwell P, Feightner J, et al. Summary of clinical preventive care recommendations for newly arriving immigrants and refugees to Canada. CMAJ 2010; June 10 [Epub ahead of print]

2. International migrant stock: The 2008 revision. New York (NY): United Nations Population Division; 2009. Available: http://esa.un.org/migration/ (accessed 2010 May 2).

3. Murphy FA, Nathanson N. The emergence of new virus diseases: an overview Semin Virol 1994;5:87-102.

4. Newbold KB, Danforth J. Health status and Canada's immigrant population. Soc Sci Med 2003;57:1981-95.

5. Beach MC, Gary T, Price E, et al. Improving health care quality for racial/ethnic minorities: a systematic review of the best evidence regarding provider and organization interventions. BMC Public Health 2006;6:104.

6. Ohmans P. Action steps to improve the health of new Americans. In: Walker PF, Barnett E, editors. Immigrant medicine. Elsevier; 2007. p. 27-35.

7. Dookeran NM, Battaglia T, Cochran J, et al. Chronic disease and its risk factors among refugees and asylees in Massachusetts, 2001-2005. Prev Chronic Dis 2010;A51.

8. Walker P. Preventive health care and management of chronic diseases in adults. In: Walker PF, Barnett E, editors. Immigrant medicine. Elsevier; 2007. p. 537-66.

9. National Health and Nutrition Examination Survey. Atlanta (GA) Center for Disease Control. Available: www.cdc.gov/nchs/nhanes.htm (accessed 2010 May 12).

Correspondence to: Dr. Patricia F. Walker, HealthPartners Center for International Health, 451 North Dunlap St., St. Paul MN 55104; Patricia.F.Walker@HealthPartners.com 